\title{
Three-year closure for Cape Flats gangland resuscitation/trauma hospital
}

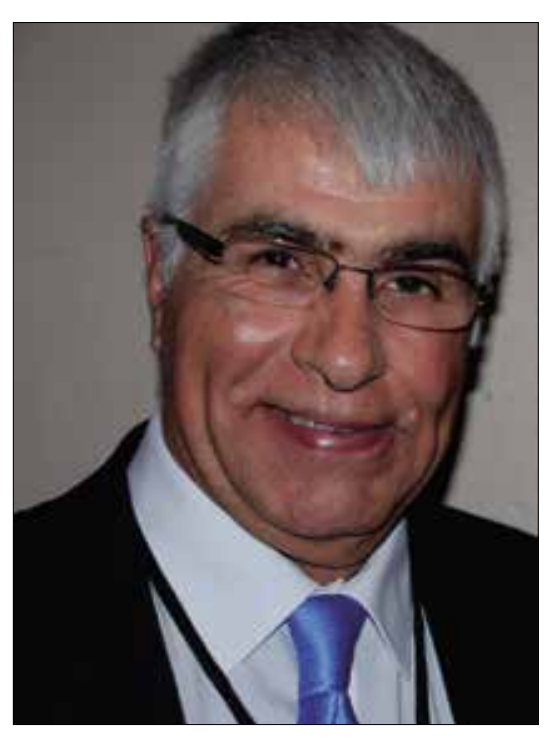

Professor Craig Househam, Director-General of Health, Western Cape.

One of the Cape Metropole's busiest district hospitals and a long-standing trauma and emergency care hub for the gang-ridden Cape Flats, G F Jooste, is to be decommissioned and reconstructed over three years from next April, posing complex healthcare capacity problems.

The Western Cape health department went to great lengths to outline its early decanting plans for patients and staff, but failed to placate a small army of alarmed stakeholders (including university undergraduates and registrars) who want the facility kept open during staged rebuilding.

As of mid-September the official strategy was three-pronged: decommission the 200bed G F Jooste, move most of the 531 staff members (including 75 medical officers and specialists) to the new Mitchell's Plain district hospital (due for commissioning in June next year) and to Groote Schuur Hospital. A stand-alone, 30 overnight-bed emergency facility would be built alongside the existing Heideveld Community Health Centre to cater for the high load of mainly alcohol- and drug-fuelled trauma in the greater Manenberg and Klipfontein areas. The existing eight-bed high-care unit at G F Jooste will relocate to Groote Schuur, where an additional 30 standard beds will be created. The balance of G F Jooste's services will be 'supplemented' at the new 300-bed Khayelitsha District Hospital (already running at maximum capacity) and wherever else spare capacity can be found or created. Izindaba checked with doctors with experience in emergency medicine at G F Jooste and they were cautiously optimistic that the new Heideveld emergency centre would adequately cover the 'golden hour' of resuscitation, enabling stabilisation of patients for transfer to higher care facilities.

'At present they're drawing up the staff establishment needed there. There's this process where staff from $G$ F Jooste will be given the option of where they'd like to go ... a 'match-and-place kind of thing. The plan is definitely to ensure sufficient capacity and I think the Heideveld interim emergency centre will be well equipped to provide stabilisation in that golden hour,' a district hospital veteran involved in the planning told Izindaba.

\section{Stakeholders put up a united front}

Anxious stakeholders consisting of the South African Medical Association (SAMA), the Cape Metro Health Forum, the Desmond Tutu HIV Foundation and the Treatment Action Campaign (TAC), formed an umbrella grouping, dubbed the G F Jooste Coalition, to oppose the plans.

Dr Zameer Brey, SAMA's Western Cape chairperson, and Dr Mark Sonderup, SAMA's national vice-chairperson, were sceptical as to how the more than one million people currently served by the district hospital would be accommodated. They were 'appalled' by the initial lack of consultation with staff and communities. Brey said the shuffling of patients to other hospitals would negatively impact on health services offered at those facilities. 'We estimate that G F Jooste caters for about 80000 patients a year and services over a million. Imagine what will happen to health services if all of a sudden patients from $G$ F Jooste are transferred to these facilities, which are already overburdened? Everything will fall apart.' Sonderup said that while upgrading made sense, 'a total shutdown does not'. His sentiments were echoed by Damaris Fritz, Western Cape chairperson of the South African NGO Coalition, who accused the health department of having been 'forced' to announce the closure after 'dodging the issue' for months. TAC deputy chairperson, Victor Lakay, said that citing the newly opened but hugely understaffed and under-resourced Khayelitsha District Hospital as a 'capacity absorber' was a political smokescreen. Transport for the majority of indigent and poor patients in the Klipfontein District would become an even greater financial burden. 'Because of apartheid planning, we don't have proper healthcare services in townships - and the net effect of Jooste's closing will be fewer beds,' he predicted.

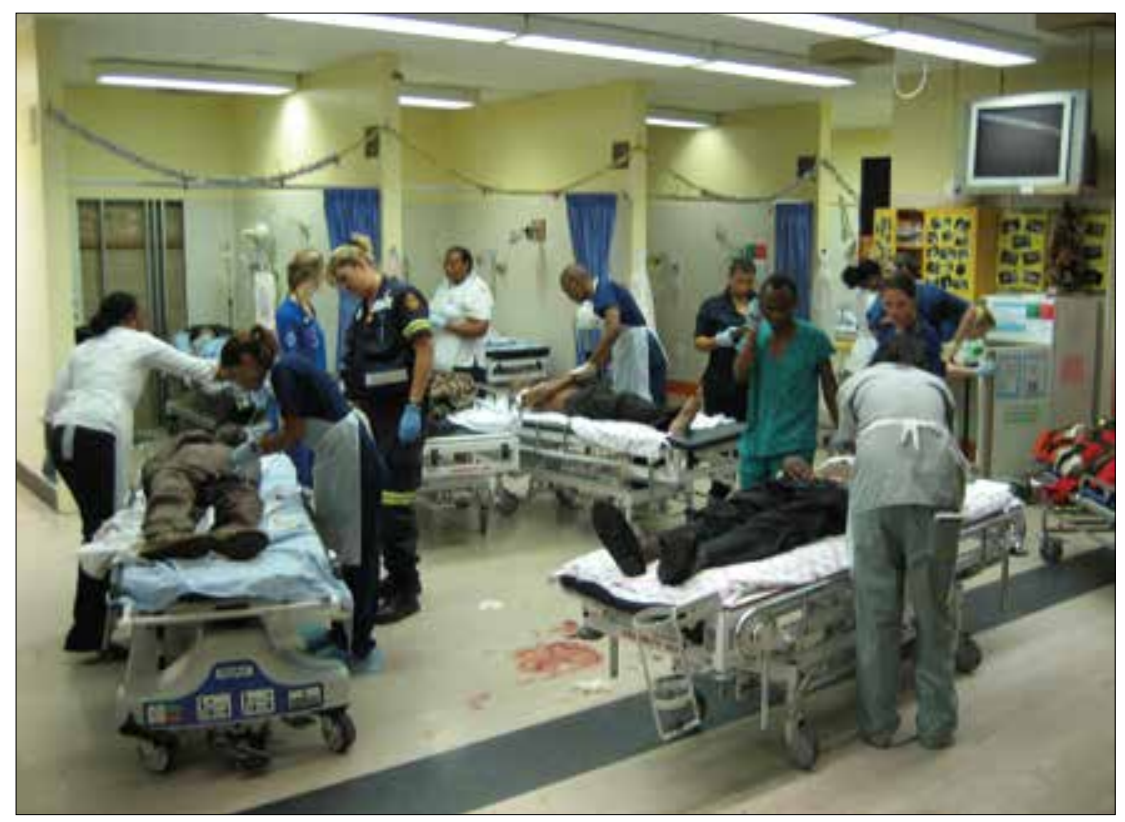

Triage typical of every weekend at $G F$ Jooste Hospital. 
Officials hold the line on demolition 'necessity'

Early September saw about 100 protestors gather in Wale Street in front of the provincial legislature, calling on Health MEC Theuns Botha to accept a memorandum to stop the proposed closure. His spokesperson, Hélène Rossouw, said the G F Jooste building was obsolete. Only demolition and rebuilding (to provide 260 additional beds and a full package of district care adding muchneeded paediatric and obstetric services), would begin to properly address burgeoning problems. She said decommissioning and demolition were by far the most cost- and time-effective options. Addressing the legislature in response to protests and media criticism, Botha denied that a three-year closure would reduce bed numbers in the Eastern Metro. He said the increased patient loads at Groote Schuur and Mitchell's Plain hospitals (both within $15 \mathrm{~km}$ of G F Jooste) would be dealt with by the decanted G F Jooste Hospital staff. Nobody would lose their jobs. G F Jooste currently provided acute and chronic health services, including management of rape victims, surgery and outpatient services. Botha said the hospital's 'very busy' emergency unit was currently 'sub-optimal' and would be greatly improved. $\mathrm{He}$ emphasised that the total number of patients seen at G F Jooste had dropped from 3500 per month to 2200 per month since the opening of the new Khayelitsha District Hospital. The re-building of G F Jooste on-site would cost about R550 million.

Ms Mercia Isaacs, chairperson of the $G$ F Jooste Hospital Facility Board, said the communities served 'deserve a bigger and better hospital with extra facilities such as maternity services, more operating theatres, better and more modern equipment and a greater number of beds. Her board was 'deeply committed' to engaging all stakeholders in the process 'leading up to' the development of plans for the new hospital.

\section{Teaching platform}

'significantly weakened'?

Concerned healthcare teachers at the University of Cape Town (UCT), University of the Western Cape (UWC) and the Cape Peninsula University of Technology (CPUT) were due to meet the Western Cape Health Department Director-General, Professor Craig Househam, on 3 October to discuss alternative placement for under- and postgraduate students.

Professor Vanessa Burch, of the Department of Medicine at UCT, who was to lead the higher education team in

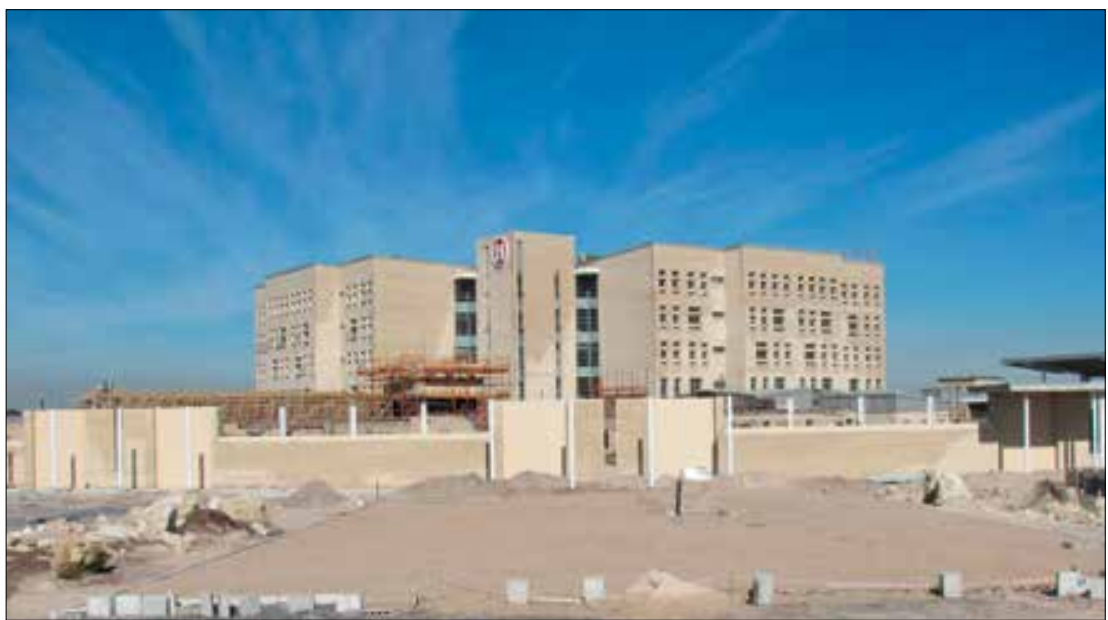

The new Mitchell's Plain District Hospital, due for opening in June next year.

discussions with Househam, told Izindaba it would be 'premature' to comment, but she had been assured that alternative plans for in-house training would be made.

While conceding that G F Jooste was a strong component of the overall training platform (with excellent first-hand exposure to a wide range of conditions), she declined to respond to concerns that there was little or no capacity to take in more under- or postgraduate students at Groote Schuur, Victoria or Somerset hospitals, especially in internal medicine, surgery and orthopaedics.

\section{Izindaba checked with doctors with experience in emergency medicine at $G$ F Jooste and they were cautiously optimistic that the new Heideveld emergency centre would adequately cover the 'golden hour' of resuscitation, enabling stabilisation of patients for transfer to higher care facilities.}

Ms Faiza Steyn, a spokesperson for the provincial health department, confirmed that no students would be placed at any new district hospital during its 'immediate' commissioning period, which she described as a 'complex process'. 'It would not be fair to either the students or indeed the hospital staff and patients to do so, she added. Her department's relevant overall education policy was to allow for the stabilisation of services in all three new district hospitals.

She could not confirm whether the October meeting would thrash out current suggestions that the experienced and decanted G F Jooste staff at the new Mitchell's Plain Hospital take on some of the teaching workload, citing current policy. 'The department will reach an appropriate agreement with the higher education institutions in the coming weeks that will allow for the continuation of on-site teaching for the duration of the rebuilding of $G F$ Jooste Hospital,' she said, adding that she was confident an 'appropriate solution' would be found.

\section{Khayelitsha takes over trauma mantle}

Prior to the opening of Khayelitsha District Hospital earlier this year, G F Jooste served 16 TB clinics and 10 ARV clinics and admitted up to 35 mainly co-infected patients daily ( $83 \%$ were co-infected). A mortality audit showed that among the HIV-positive adults who died at the hospital, the leading cause of death was TB (56\%). G F Jooste has a TB incidence of 1800 per 100000 people per year compared with Khayelitsha's 1612 per 100000 people per year. Khayelitsha has the leading provincial antenatal HIV seroprevalence at $33 \%$. This, and the huge burden of trauma in the sprawling black township nestled up against False Bay and bordering Mitchell's Plain, are among the chief reasons a district hospital was built there. Within months of commissioning, Khayelitsha District Hospital was already seeing more emergency (medical and surgical) patients than G F Jooste, long considered the hub of trauma/emergency care in the Western Cape (7 111 for June and July this year versus 4660 for the same period at G F Jooste Hospital).

\section{Chris Bateman}

chrisb@hmpg.co.za

S Afr Med J 2012;102(11):823-824.

DOI:10.7196/SAMJ.6363 